\title{
EL ARTÍCULO 41 DE LA CARTA DE LOS DERECHOS FUNDAMENTALES DE LA UNIÓN EUROPEA: UNA VISIÓN CRÍTICA
}

\author{
Susana Viñuales Ferreiro
}

\begin{abstract}
SUMARIO: 1. INTRODUCCIÓN. 2. REFLEXIONES SOBRE EL DERECHO A UNA BUENA ADMINISTRACIÓN. 2. 1. Antecedentes de la buena administración en el Derecho positivo. 2.2. El reconocimiento a través de la jurisprudencia del principio de buena administración y de los derechos que lo componen. 2.3. La proclamación de la buena administración en la Carta de los Derechos Fundamentales de la Unión Europea: repercusiones. 2. 4. Un derecho fundamental sin contenido especifico cuya relevancia se sitúa en los derechos públicos subjetivos que lo integran. 3. A MODO DE CONCLUSIÓN.
\end{abstract}

\section{INTRODUCCIÓN}

La Carta de los Derechos Fundamentales de la Unión Europea recoge en su Capítulo V -relativo a la «ciudadanía» el derecho a una buena administración (art. 41). De este modo, se introduce en el ordenamiento jurídico europeo, con la categoría de derecho fundamental, un nuevo derecho que hasta entonces solo había tenido un reconocimiento -parcial- en el campo jurisprudencial.

Como sabemos, la Carta de los Derechos Fundamentales de la Unión Europea fue proclamada en el Consejo Europeo de Niza el 7 de diciembre de 2000 conjuntamente por el Consejo, el Parlamento Europeo y la Comisión ${ }^{1}$.

${ }^{1}$ Previamente había sido aprobada separadamente por cada una de las Instituciones: el Consejo por unanimidad, en el Consejo «informal» de Biarritz celebrado los días 13 y 
Sin embargo, la pretensión del Parlamento Europeo de que la Carta pasara a formar parte de los Tratados fue rechazada por el Reino Unido, Irlanda, Holanda, Dinamarca, Finlandia y Suecia.

Posteriormente, el Tratado por el que se establece una Constitución para Europa incluyó la Carta como Parte II del mismo pero desgraciadamente, los esfuerzos de la Convención no llegaron a consolidarse. Así pues, tras el intento fallido de que la que Carta pasara a formar parte del texto de los Trata$\operatorname{dos}^{2}$, el Tratado de Lisboa vino a solucionar la cuestión. La Carta se mantiene actualmente en un texto independiente ${ }^{3}$ pero es dotada de valor jurídico vinculante en virtud de lo dispuesto en el art. 6.1 del TUE, que establece:

«La Unión reconoce los derechos, libertades y principios enunciados en la Carta de los Derechos Fundamentales de la Unión Europea de 7 de diciembre de 2000, tal como fue adaptada el 12 de diciembre de 2007 en Estrasburgo, la cual tendrá el mismo valor jurídico que los Tratados»

Como indica Dutheil De La Rochère, la Carta no es propiamente parte del Derecho primario pero adquiere el estatus de tal ${ }^{4}$.

Así, con la entrada en vigor del Tratado de Lisboa, se pone fin a la incertidumbre latente en la doctrina durante los pasados años, deseosa de que la cuestión relativa al valor jurídico de la Carta se resolviera positivamente. Hoy contamos en el ordenamiento jurídico de la Unión Europea con una declaración de derechos fundamentales a la que se ha atribuido el mismo valor jurídico que los Tratados 5 .

Ahora bien, más allá de los efectos que sobre la construcción política de la Unión Europea implique contar con tal declaración de derechos fundamentales, lo que pretendemos destacar en este estudio es que la Carta recoge en

14 de octubre de 2000, el Parlamento el 14 de noviembre de 2000 y la Comisión Europea también por unanimidad el 6 de diciembre de 2000. El texto fue publicado en el DOCE C 364 de 18.12.2000.

${ }^{2}$ La pretensión del Tratado por el que se establece una Constitución para Europa, era incluir la Carta como Parte II del mismo, pero como sabemos, los esfuerzos de la Convención no llegaron a consolidarse.

${ }^{3}$ La Carta queda incorporada el Derecho originario por remisión en virtud de la Declaración 1 aneja al Acta final del Tratado de Lisboa.

${ }^{4}$ Dutheil De La Rochère, J., «La Carta de Derechos Fundamentales de la Unión Europea: ámbito de aplicación, orígenes y otros aspectos generales», en BENEYTO PÉREZ, J.M. (Dir.), Tratado de Derecho y Politicas de la Unión Europea. Tomo II. Derechos Fundamentales, Aranzadi, Navarra, 2009, pág. 208.

${ }^{5}$ La Carta fue de nuevo proclamada en Estrasburgo por el Consejo, el Parlamento Europeo y la Comisión el 12 de diciembre de 2007, en un texto que incluía las modificaciones en sus disposiciones finales producidas como consecuencia de su adaptación al Tratado Constitucional, DO C n ${ }^{\circ} 303$, de 14 de diciembre de 2007. 
su art. 41 un derecho de nuevo cuño ${ }^{6}$ que, a diferencia de otros derechos que ya se habían dejado entrever en los Tratados u otros textos de derecho originario, es la primera vez que se recoge de forma expresa en un texto escrito ${ }^{7}$.

En las líneas que siguen trataremos de abordar las características de este nuevo derecho así como las repercusiones que su proclamación como derecho fundamental pueda tener de cara a su protección por los Tribunales de la Unión Europea.

\section{REFLEXIONES SOBRE EL DERECHO A UNA BUENA ADMINISTRACIÓN}

\subsection{Antecedentes de la buena administración en el Derecho positivo}

Como decimos, no es hasta su proclamación en el art. 41 de la Carta ${ }^{8}$, cuando el derecho a una buena administración se incluye en un listado de derechos «fundamentales».

${ }^{6}$ La idea del derecho a una buena administración había sido apuntada en una proposición finlandesa pero fue el Ombudsman Europeo quien a comienzos del año 2000, detectada la necesidad de regular la materia, propuso a la Convención encargada de elaborar la Carta la incorporación de una disposición específica sobre el derecho a una buena administración. Para un estudio global sobre el Defensor del Pueblo Europeo, véase, MELlado Prado, P., «El Defensor del Pueblo Europeo, Quince años después», Teoría y Realidad Constitucional, núm. 26, 2010, págs. 191 a 227.

7 Hay que señalar que la redacción inicial del texto del art. 41 fue objeto de diversas modificaciones pero éstas no pasaron de ser adaptaciones de carácter técnico al contexto del Tratado constitucional primero, y al Tratado de Lisboa después, sin afectar a la configuración esencial del derecho a una buena administración, GonZÁlez AlONSO, L. N., «El derecho a una buena administración», en Mangas Martin, A., Carta de los Derechos fundamentales de la Unión Europea. Comentario artículo por artículo, Fundación BBVA, Bilbao, 2008, págs. 666 y 667.

${ }^{8}$ El art. 41 de la Carta dispone: «1. Toda persona tiene derecho a que las instituciones, órganos y organismos de la Unión traten sus asuntos imparcial y equitativamente y dentro de un plazo razonable.

2. Este derecho incluye en particular:

a) el derecho de toda persona a ser oída antes de que se tome en contra suya una medida individual que la afecte desfavorablemente;

b) el derecho de toda persona a acceder al expediente que le concierna, dentro del respeto de los intereses legítimos de la confidencialidad y del secreto profesional y comercial;

c) la obligación que incumbe a la administración de motivar sus decisiones.

3. Toda persona tiene derecho a la reparación por la Unión de los daños causados por sus instituciones o sus agentes en el ejercicio de sus funciones, de conformidad con los principios generales comunes a los Derechos de los Estados miembros.

4. Toda persona podrá dirigirse a las instituciones de la Unión en una de las lenguas de los Tratados y deberá recibir una contestación en esa misma lengua.» 
Con anterioridad son también muy escasas las referencias al mismo en el Derecho positivo, siendo en el ámbito jurisprudencial dónde empieza a vislumbrarse su protección. Veamos brevemente cuáles son sus primeras manifestaciones.

Aparte de vagas referencias en textos que no llegaron a proclamarse ${ }^{9}$, el derecho a una buena administración tal y como está expresado en la Carta carece de precedentes en los documentos internacionales o europeos de derechos humanos.

Centrando la mirada en el ámbito internacional, TOMÁs MALLÉN ${ }^{10}$ destaca la dificultad de determinar los antecedentes de este derecho, pues la preocupación por tutelar a los ciudadanos frente a la acción de la Administración perecía inexistente. Así, no encontramos en los textos internacionales ninguna alusión al derecho a la buena administración en sentido genérico ni a ninguna de sus posibles manifestaciones. No existe regulación específica del mismo ni en la Declaración Universal de Derechos Humanos de 1948, ni en los Pactos Internacionales de 1966, ni tampoco en el Convenio Europeo de Derechos Humanos. Solamente, el Tribunal Europeo de Derechos Humanos «ha intentado garantizar alguno de los aspectos que lo integran a través de una meritoria labor de interpretación extensiva de otros derechos... $\rangle^{11}$.

9 Por una parte, pueden encontrarse en el Derecho derivado diversas normas que vienen a abordar distintos aspectos concretos en los que los derechos fundamentales están necesitados de una protección especial (puede citarse como ejemplo el Reglamento núm. 1 de 1958, por el que se fija el régimen lingüístico de la Comunidad Económica Europea, DO L, $\mathrm{n}^{\circ} 17$ de 6.10.1958). Pero además existen numerosos actos «atípicos» en los que se atisban ciertos aspectos relacionados con lo que será el derecho a una buena administración. Entre ellos pueden destacarse: la Declaración sobre la identidad europea adoptada en la Cumbre de Jefes de Estado y de Gobierno de Copenhague en 1973; la Declaración conjunta del Parlamento Europeo, del Consejo y de la Comisión sobre los derechos fundamentales, firmada en Luxemburgo el 5 de abril de 1977; la Declaración sobre la Democracia (sobre el respeto a los derechos fundamentales) suscrita en el Consejo Europeo de Copenhague de 1978 de forma conjunta por el Parlamento Europeo, del Consejo y de la Comisión; el Proyecto de Tratado de Unión Europea (conocido como Proyecto de Spine1li), aprobado por el Parlamento el 14 de febrero de 1984; la Declaración de Derechos y Libertades Fundamentales, adoptada por el Parlamento Europeo sobre la base del Informe De Gucht el 12 de abril de 1989; y el Proyecto de Constitución de la Unión Europea (conocido como Proyecto Herman) aprobado por la Comisión de Asuntos institucionales del Parlamento Europeo con fecha 8 de febrero de 1994 pero no logró alcanzar un amplio consenso.

${ }^{10}$ Sobre este tema, véase el excelente trabajo de esta autora, Vid., TOMÁs MALLÉN, B. El derecho fundamental a una buena Administración, MAP-INAP, Madrid 2004.

${ }^{11}$ La autora citada advierte una referencia genérica a la buena administración en la Declaración de los Derechos del Hombre y del Ciudadano, adoptada por la Asamblea Constituyente francesa el 26 de agosto de 1789, cuando señala que «la sociedad tiene derecho a pedir cuentas de su actuación administrativa a todo agente público». Sin embar- 
En cuanto al Derecho originario de la Unión Europea, tampoco se encuentra en los Tratados constitutivos referencia al derecho genérico a la buena administración.

No puede olvidarse, en este punto, la aportación del Consejo de Europa sobre los principios que integran la buena administración, como no podía ser de otro modo en un organismo internacional destinado a la protección de los derechos y libertades de los individuos. Basándose en los estándares definidos y aplicados en los Estados miembros que son parte del mismo, el Consejo de Europa ha ido definiendo los principios de la buena administración que deben guiar los procedimientos administrativos de los Estados miembros a fin de asegurar mayor equidad en las relaciones entre los particulares y las autoridades administrativas ${ }^{12}$. Ahora bien, a pesar de su importancia, pues los principios que proclama se dirigen a promover la buena administración, las Recomendaciones del Consejo de Europea no constituyen normas jurídicamente vinculantes.

Tampoco las leyes nacionales se refieren a la buena administración como derecho fundamental ${ }^{13}$. En el supuesto concreto del ordenamiento jurídico español, si bien encontramos algunas disposiciones constitucionales sobre derechos que integrarían lo que puede entenderse por buena administración, éstas no se encuentran recogidas entre los derechos «fundamentales».

\subsection{El reconocimiento a través de la jurisprudencia del principio de buena administración y de los derechos que lo componen}

De las circunstancias descritas puede deducirse que la relevancia de la jurisprudencia de la Unión Europea va a ser de especial magnitud. Han sido

go, como bien indica, se trata más de una regla democrática que de un derecho individual, Idem, pág. 179.

12 En este sentido hay que destacar la Resolución del Comité de Ministros de 28 de septiembre de 1977 (77/31) sobre la protección de los particulares en relación con los actos de las autoridades administrativas; la Recomendación del Comité de Ministros de 11 de marzo de 1980 (R (80)2), relativa al ejercicio de poderes discrecionales por las autoridades administrativas; y en especial la Recomendación del Comité de Ministros a los Estados miembros sobre una buena administración adoptada el 20 de junio de 2007 (CM/ Rec (2007)7). Vid., Ponce Solé, J., «EU Law, Global Law and de Right to Good Administration», en Chiti, E., Giorgo Mattarella, B. (Editors), Global Administrative Law and EU Administrative Law. Relationships, legal Issues and Comparison, Springer, London, New York, 2011, pág. 138.

13 Así se constata en el estudio efectuado por Dutheil De LA Rochère, J., «The charter of Fundamental Rights, Non binding but influential: the Example of Good Administration», en Continuity and Change in EU Law: Essays in Honour of sir Francis Jacobs, Ed. Arnull, Eeckhout y Tridimas, Oxford University Press, 2008, pág. 168. 
los jueces europeos quiénes han ido allanando el camino para su construcción y su posterior integración en la Carta de los Derechos Fundamentales ${ }^{14}$.

Pues bien, tradicionalmente la jurisprudencia europea se ha referido al mismo como un principio informador ${ }^{15}$. Ya con anterioridad a la proclamación de la Carta, encontramos numerosas sentencias en las que aparece la referencia al término «buena administración», pero no como derecho en sí mismo sino, más bien como estándar de comportamiento exigido a la Administración en sus relaciones con los Estados miembros, sus organismos y agentes, o con los propios administrados, es decir como principio orientador de la actuación administrativa ${ }^{16}$.

Del mismo modo, casi desde el inicio de las Comunidades Europeas encontramos referencias a la buena administración en el marco de la defensa de alguno de los derechos que lo integran. Por tanto, aunque algunos derechos del actual art. 41 de la Carta están recogidos en el Derecho originario, su principal construcción la encontramos en la esfera jurisprudencial.

Por ejemplo, el Tribunal de Justicia se pronuncia muy tempranamente sobre la obligación de motivar aludiendo al principio de buena administración en la sentencia Industrias Siderúrgicas asociadas c. Alta Autoridad ${ }^{17}$. Posteriormente, el Tribunal concibe esta obligación como una de las exigencias del Derecho comunitario, pues solo abarcando la legalidad de los motivos de la decisión impugnada el control jurisdiccional podrá ser eficaz ${ }^{18}$.

14 Vid., TOMÁs Mallén, B., op. cit., pág. 179.

15 Como señala TRIDIMAS, a diferencia de otros principios, el principio de buena administración no se ha construido con referencia a los sistemas jurídicos de los Estados miembros, Vid., Tridimas, T., The General Principles of EU Law, Segunda Edición, Oxford University Press, NY, 2006, pág. 411.

${ }^{16}$ En este sentido, pueden destacarse las sentencias del Tribunal de Justicia Maurissen c. Tribunal de Cuentas, de 4 de febrero de 1987, asunto 417/85; Burban, de 31 de marzo de 1992, asunto C-255/90 P, Interporc, de 31 de marzo de 1992, asunto C-255/90 P; o las sentencias del Tribunal de Primera instancia BonnFleish, de 27 de febrero de 2003, asunto T-329/00; Nölle, de 18 de septiembre de 1995, asunto T-167/94 o New Europe Consulting, de 9 de julio de 1999, asunto T-231/1997, entre otras.

17 Sentencia de 11 de febrero de 1955.

18 Vid., entre otras, las Sentencias del Tribunal de Justicia de 15 de octubre de 1987, Heylens, asunto 222/86 (ap. 15 y 16), o la de 21 de noviembre de 1991, TV Munchen, C-269/90. En este última, el Tribunal se refiere a dos manifestaciones del derecho a una buena administración que deben ser respetadas en el marco del procedimiento administrativo desarrollado ante una institución comunitaria (en este caso la Comisión), a saber, el derecho a ser oído que exige que la parte interesada esté en situación «de definir su postura y manifestar eficazmente su punto de vista sobre la importancia de los hechos así como, en su caso, sobre los documentos en los que se basa la Institución comunitaria», y la motivación, en cuya virtud, debe constar de modo claro e inequívoco el razonamiento de la autoridad comunitaria de quien procede el acto impugnado, a fin de permitir a los intere- 
También los Tribunales aludieron a que la obligación de la Administración de resolver en un tiempo razonable deriva de las reglas de la buena administración ${ }^{19}$.

Por otra parte, encontramos referencias al derecho a ser oido como expresión del derecho de defensa, en este caso en el procedimiento administrativo en materia de defensa de la competencia, ya en la Sentencia del Tribunal de Justicia de 18 de octubre de 1989, Orkem, asunto 374/8720. Por ejemplo, en la ya citada sentencia New Europe Consulting el Tribunal de Primera instancia reproduce su reiterada jurisprudencia según la cual el respeto al derecho de defensa en todo procedimiento que pueda terminar en un acto lesivo contra una persona «constituye un principio fundamental del Derecho comunitario que debe garantizarse aun cuando no exista una normativa relativa al procedimiento de que se trate $\rangle^{21}$.

El Tribunal de Justicia ya se había pronunciado en la misma línea en ocasiones anteriores $^{22}$. En la sentencia Reino de los Países Bajos y otros c. Comisión $^{23}$, el Tribunal aprecia, en el marco de un procedimiento de competencia, una vulneración del derecho de defensa en cuanto que la Comisión no envió al Estado miembro (Países Bajos) una comunicación con una exposición precisa y completa de los cargos que se proponía formular contra él, concediéndole la oportunidad de ser oído. En la sentencia Fiskano, ya citada, el Tribunal deduce de toda la jurisprudencia sobre el derecho de defensa, la exigencia de que toda persona a quién se le pueda imponer una sanción, tenga ocasión de dar a conocer de modo útil su punto de vista sobre los elementos considerados por la Comisión para imponer la sanción.

De este modo, vemos cómo es en el ámbito jurisprudencial donde se ha ido gestando la noción de buena administración como concepto genérico y donde se han ido delimitando algunos de los derechos que la componen como

sados conocer las justificaciones de la medida adoptada para que puedan defender sus derechos, e igualmente permitir al Tribunal ejercer su control.

19 Vid., Sentencia del Tribunal de Justicia de 10 de mayo de 1960, caso Alemania c. Alta Autoridad, asunto C-19/58. Por su parte en la Sentencia de 10 de mayo de 1960, el Tribunal de Justicia destaca que para cumplir con las exigencias de una Administración eficiente, la decisión debe notificarse a los interesados en el plazo más breve posible, caso Hauts Fourneuax de Givors y otros c. Alta Autoridad, asunto C-27/58.

${ }^{20}$ En el mismo sentido, sentencias del Tribunal de Justicia son la de 12 de febrero de 1992, Países Bajos y Otros c. Comisión, asuntos acumulados C-48/90 y C-66/90, y la de 29 de junio de 1994, Fiskano c. Comisión, asunto C-135/92.

${ }^{21}$ Asunto T-231/1997 (ap. 41, 42 y 44).

22 Vid., por ejemplo, las sentencias de 13 de febrero de 1979, Hoffmann-La Roche c. Comisión, asunto 85/76, de 21 de septiembre de 1989, Hoechst. Comisión, asuntos acumulados 46/87 y 227/88, de 14 de febrero de 1990, Francia c. Comisión, asunto-301/87.

${ }^{23}$ Asuntos acumulados C-48/90 y 66/90. 
principios rectores de la actividad administrativa que van a surtir efectos en el procedimiento administrativo. Sin embargo, coincidimos con CARRILlO DONAIRE en que, si bien aparecen de forma reiterada términos como «principio de buena administración»o «deber de buena administración», y los Tribunales reconocen el resarcimiento cuando se originen perjuicios al incumplir reglas vinculantes para la Administración, no se llega a proclamar la buena administración como derecho subjetivo que pueda traducirse en facultades definidas y exigibles por los ciudadanos ${ }^{24}$.

\subsection{La proclamación de la buena administración en la Carta de los Derechos Fundamentales de la Unión Europea: repercusiones}

Con su integración en la Carta, el derecho a una buena administración pasa del ámbito jurisprudencial al Derecho positivo, con los efectos en cuanto a la transparencia y visibilidad que ello conlleva.

Por una parte, tiene consecuencias en el ámbito institucional, donde los principios de transparencia y participación se verán reforzados. Precisa GuILLEM CARRAU, que la introducción en la Carta del derecho a la buena administración va a vincular en la toma de decisiones tanto a la Comisión Europea como al resto de instituciones, comprometidas a promover su desarrollo y respetar su contenido ${ }^{25}$.

Pero además, la buena administración se configura, al menos formalmente, como un derecho fundamental.

Ahora bien ¿qué repercusiones tiene tal configuración?

Debido a que en el ámbito de la Unión Europea carecemos de antecedentes de declaraciones de derechos fundamentales, recurriremos a los ordenamientos jurídicos internos como parámetro de referencia. Así, los derechos fundamentales son aquéllos que forman parte de los catálogos de derechos que las Constituciones de los respectivos Estados consideran como tales, frente al resto de derechos subjetivos o principios que son creados en beneficio del ciudadano por leyes ordinarias o normas de rango inferior $^{26}$.

${ }^{24}$ Vid., CARrillo Donaire, J. A., «Buena administración, ¿un principio, un mandato o un derecho subjetivo?», en Santamaría Pastor, J. A., (Dir.), Principios jurídicos del Derecho Administrativo, La Ley, Madrid, 2010, pág. 1144.

${ }_{25}$ Guillem Carrau, J., «El avance del derecho a la buena administración en el Tratado de Lisboa», Revista de Derecho de la Unión Europea, nº 19, 2010, pág. 44. Se ha resaltado como poco después de aprobarse la Carta, la mayoría de las Instituciones fueron adoptando sus respetivos Códigos europeos de buena conducta administrativa.

${ }^{26}$ Vid., Fernández Tomás, A., La Carta de derechos fundamentales de la Unión Europea, Tirant lo Blanch, Valencia, 2001, pág. 21. 
El criterio formal ha de complementarse con otro relativo a los especiales medios de protección previstos en unos y otros casos. Los derechos fundamentales son aquéllos que en los ordenamientos internos cuentan con el máximo nivel de protección y garantía. De modo que su principal relevancia no reside tanto en que sean considerados formalmente como tales, sino en las distintas consecuencias que tiene la violación de cada una de esas clases de derechos.

Trasladando los criterios enunciados al Derecho de la Unión Europea, la primera constatación es que todos los derechos recogidos en la Carta, y entre ellos, el derecho a una buena administración, tienen formalmente la consideración de derechos fundamentales.

Sin embargo, la proclamación de la Carta y la posterior adquisición de valor jurídico vinculante no ha llevado aparejada la instauración de medios específicos de protección para los derechos que proclama -no existe un recurso de amparo europeo--. Esto se debe fundamentalmente a que el concepto de derecho fundamental en el ámbito comunitario no está dogmáticamente elaborado. Una aproximación doctrinal a la materia nos lleva, por tanto, a afirmar que en el Derecho europeo la calificación de un derecho como «fundamental» no comporta consecuencias jurídicas específicas que lo puedan diferenciar de otros derechos subjetivos ordinarios ${ }^{27}$. La vulneración de cualquier derecho fundamental se hará valer a través de los mecanismos propios del ordenamiento jurídico de la Unión Europea ya establecidos.

Con relación al derecho a una buena administración, a la ya mencionada ausencia de vías específicas de protección de los derechos fundamentales, se une la indeterminación y amplitud de su contenido, que solamente preludia el art. 41. Todo ello determina la dificultad para ser alegado como tal derecho por los particulares, y por tanto, para su garantía específica por los Tribunales.

Lo dicho nos conduce a afirmar que nos encontramos más bien ante un principio rector de la actuación de la Administración europea, -entendida ésta en sentido amplio-, más cercano al concepto de buen gobierno, o «buena gobernanza $\rangle^{28}$. Todo ello en línea con la construcción jurisprudencial que desde su origen se ha centrado en el logro de una gestión pública más óptima en beneficio de los ciudadanos ${ }^{29}$.

Puede afirmarse, por tanto que la configuración formal del derecho a una buena administración como derecho fundamental carece hasta el momento

${ }^{27}$ Idem, pág. 138.

28 Vid., Comunicación de la Comisión de 25 de Julio de 2001, «La Gobernanza europea-Un libro Blanco», COM (2001) 428 final, DO C 287, de 12.10.2001.

29 En este sentido, Dutheil De La Rochère, J., «La Carta de los derechos....», op. cit., pág. 170 . 
de consecuencias específicas en el ámbito de la Unión Europea, ante la carencia, como veremos, de un instrumento específico para su protección.

\subsection{Un derecho fundamental sin contenido especifico cuya relevancia se sitúa en los derechos públicos subjetivos que lo integran}

No obstante lo expuesto, la buena administración se presenta en el art. 41 como un concepto genérico que da cobertura a una serie de derechos que, generalmente alcanzan su máxima expresión en el procedimiento administrativo. Creemos que la relevancia del art. 41 reside precisamente en esos derechos concretos que el propio texto se encarga de precisar en una lista abierta. Son los derechos a que los asuntos sean tratados de modo imparcial, equitativo y dentro de un plazo razonable, de acceso al expediente, de audiencia, la obligación de la Administración de motivar sus decisiones, el derecho al uso en las comunicaciones con las Instituciones de las lenguas previstas en los Tratados, y a obtener una reparación de los daños causados por las Instituciones o sus agentes.

Con relación a su contenido, las Explicaciones sobre la Carta de los Derechos Fundamentales ${ }^{30}$ nos indican que algunos de ellos tienen un origen exclusivamente jurisprudencial mientras que otros reproducen, aunque no exactamente, varios preceptos de los Tratados. Por tanto, con el art. 41 se confiere unidad a una serie de derechos que se encontraban, bien dispersos en los Tratados, bien reconocidos a los particulares a través de su desarrollo jurisprudencial.

La reflexión que se nos plantea es si a tenor de su proclamación en la Carta, los derechos recogidos en el art. 41 pueden considerase derechos públicos subjetivos y, en consecuencia, ser directamente alegables por los particulares ante los Tribunales ${ }^{31}$.

La primera apreciación es que los derechos contemplados no gozan todos ellos de la misma naturaleza jurídica. Tenemos que distinguir nuevamente entre un principio de carácter general, como es el derecho de los particulares a que sus asuntos sean tratados, imparcial y equitativamente, lo que vendría a conformar el derecho a contar con una Administración eficaz, diligente y transparente, del resto de los derechos reproducidos. La imprecisión del contenido de los primeros hace que no podamos hablar de derechos directamente alegables por los particulares. Una vez más, estaríamos ante principios

${ }_{30}$ 2007/C 303/02), DO, C 303/17, de 14.12.2007.

31 Tal virtualidad de la Carta ha sido resaltada por algunos autores, DutHEIL DE LA Rochère, J., «La Carta de los derechos...», op. cit., págs.. 168 y 169; HofmanN, H;. Rowe, G. Y TÜrk, A., Administrative Law and Policy of the European Union, Oxford University Press, New York, 2011, pag. 194. 
objetivos de funcionamiento de la Administración cuya concreción hasta la fecha solo se ha producido a través de normas de soft law. Sin embargo, no puede decirse lo mismo de los otros derechos proclamados en el art. 41, en especial el derecho a que los asuntos sean tratados dentro de un plazo razonable, el derecho de audiencia al afectado por una medida desfavorable, el derecho de acceso al expediente antes de la adopción de una medida desfavorable, el deber de la Administración y correlativo derecho de los particulares a que las decisiones administrativas estén motivadas, el derecho a la reparación de los daños causados por las instituciones de la Unión Europea o sus agentes, o el derecho a usar, en las comunicaciones con las Instituciones, las lenguas previstas en los Tratados.

Consideramos que se trata en todos los casos de derechos de carácter procedimental, es decir derechos que despliegan todos sus efectos y cobran sentido principalmente en el marco de un procedimiento administrativo. En nuestra opinión, pueden calificarse de verdaderos derechos públicos de carácter subjetivo, que, a priori podrían ser directamente alegables por los particulares frente a la Administración Europea, aunque en la práctica la vulneración de tales derechos se pone de manifiesto a través del control de los vicios del procedimiento.

\section{A MODO DE CONCLUSIÓN}

La inclusión en el art. 41 de la Carta del derecho a una buena administración con la misma fuerza vinculante de los Tratados no debe pasar desapercibida. Entendemos que sus consecuencias pueden ser altamente positivas para los ciudadanos europeos, aunque de momento parezcan residir más bien en el plano de la dogmática jurídica.

Ahora bien, no cabe duda de que la buena administración constituye una noción ambigua que incorpora dos realidades o ámbitos distintos. Así por una parte, se encuentra la buena administración como principio de amplio espectro, mas cercano al concepto de buen gobierno o buena gobernanza, y que hace referencia a esos aspectos éticos o deontológicos que deben regir el ejercicio del poder a fin de limitar la discrecionalidad administrativa. Por otra, la buena administración se concreta en un conjunto de derechos subjetivos, con sus respectivas garantías procedimentales, que generan obligaciones específicas para la Administración europea.

En consecuencia, puede decirse que desde su proclamación en la Carta, la Administración europea queda vinculada, en la aplicación directa del Derecho europeo, al respeto de los mencionados derechos procedimentales, así como de aquellos otros que, bien legislativamente bien a través de la jurisprudencia, puedan establecerse en desarrollo del art. 41, quedando su actuación sometida al control de los Tribunales de la Unión Europea. 


\section{BIBLIOGRAFÍA}

Carrillo Donaire, J. A., «Buena administración, iun principio, un mandato o un derecho subjetivo?», en SANTAMARÍA PAStor, J. A., (Dir.), Principios jurídicos del Derecho Administrativo, La Ley, Madrid, 2010, pp. 1137 a 1165.

Dutheil De La Rochére, J., «The charter of Fundamental Rights, Non binding but influential: the Example of Good Administration», en Continuity and Change in EU Law: Essays in Honour of Sir Francis Jacobs, Ed. Arnull, Eeckhout y Tridimas, Oxford University Press, 2008, pp. 157 a 171.

— «La Carta de Derechos Fundamentales de la Unión Europea: ámbito de aplicación, orígenes y otros aspectos generales», en BENEYTo PÉREZ, J. M. (Dir.), Tratado de Derecho y Políticas de la Unión Europea. Tomo II. Derechos Fundamentales, Aranzadi, Navarra, 2009, pp. 161 a 217.

Fernández TomÁs, A., La Carta de derechos fundamentales de la Unión Europea, Tirant lo Blanch, Valencia, 2001.

Guillem CARRAU, J., «El avance del derecho a la buena administración en el Tratado de Lisboa», en Revista de Derecho de la Unión Europea, No 19, 2010, pp. 31 a 70.

Hofmann, H. C. H.; Rowe, G.G. y Türk, A. H., Administrative Law and Policy of the European Union, Oxford University Press, New York, 2011.

Mangas Martín, A., Carta de los Derechos fundamentales de la Unión Europea. Comentario artículo por artículo, Fundación BBVA, Bilbao, 2008.

Mellado Prado, P., «El Defensor del Pueblo Europeo, quince años después», en Teoría y Realidad Constitucional, núm. 26, 2010, pp. 191 a 227.

Ponce SolÉ, J., «EU Law, Global Law and de Right to Good Administration», en Chiti, E., Giorgo MatTARella, B. (Editors), Global Administrative Law and EU Administrative Law. Relationships, legal Issues and Comparison, Springer, London, New York, 2011, pp. 133 a 145.

TOMÁs MAlLÉn, B., El derecho fundamental a una buena Administración, MAPINAP, Madrid 2004.

Tridimas, T., The General Principles of EU Law, Segunda Edición, Oxford University Press, NY, 2006.

TITLE: Article 41 of the Charter of Fundamental Rights of the European Union: a critical approach.

RESUMEN: La Carta de los Derechos Fundamentales de la Unión Europea introduce en el ordenamiento jurídico europeo un "nuevo derecho» que hasta entonces solo había sido reconocido, de forma parcial, a través de la jurisprudencia: el derecho a una buena administración. El presente trabajo tiene por objeto el estudio de este derecho, centrando la atención en las características con las que se configura y las repercusiones que su proclamación como derecho fundamental tiene de cara a su protección por los Tribunales de la Unión Europea. 
Palabras ClaVE: Carta de los Derechos Fundamentales de la Unión Europea. Derecho a una buena administración. Derechos fundamentales. Tribunal de Justicia de la Unión Europea.

ABSTRACT: The Charter of Fundamental Rights of the European Union introduces into the European legal system a «new right» which so far had only been recognized, partially, through jurisprudence: the right to good administration. This article aims the analyzes this right, focusing on how it has been configured and the impact of its recognition as a fundamental right on the protection by the Courts of the European Union.

KEY WORDS: Charter of Fundamental Rights of the European Union. Right to good administration. Fundamental rights. Court of Justice of the European Union.

RECIBIDO: 21.05.2015

ACEPTADO: 04.06.2015 
